\title{
Dünya Mirası Kırsal Kültürel Peyzajları ve Selge Tarım Terasları
}

\section{World Heritage Rural Cultural Landscape and Selge Agricultural Terraces Sila BALTA ${ }^{a *}$, Meryem ATIK ${ }^{b}$}

\footnotetext{
a Akdeniz Üniversitesi Mimarlık Fakültesi Peyzaj Mimarlığı Bölümü, 07070 Antalya

b Akdeniz Üniversitesi Mimarlık Fakültesi Peyzaj Mimarlığı Bölümü, 07070 Antalya
}

Article history: Received 28-12-2018 / Accepted 11-07-2019

\section{ÖZET ABSTRACT}

Bu çalışmada Dünya Mirası Kültürel Mirasları listesinde yer alan ve kırsal nitelik taşıyan kültürel peyzaj alanlarının değerlendirilmesi ile Dünya Mirası kültürel peyzajları açısından tarımsal ve kırsal özellikleri itibariyle binlerce yıldır süregelen geleneksel alan kullanım deseni ile Selge geleneksel tarım terasları incelenmiştir.

Çalışmada, Dünya Miras Listesindeki miras alanları seçilme kriterleri doğrultusunda yorumlanmaktadır. Arazi çalışmaları ve yapılan kaynak incelemeleri ile ortaya konan ve Selge antik kentinin belirgin bir özelliği olan geleneksel tarım terasları ve antik özellikleri açıSIndan UNESCO tarafından belirlenen kriterler doğrultusunda uygunluğu değerlendirilmiştir. Selge antik kentinin ve geleneksel tarım teraslarının Dünya Miras Listesinde yer alan kırsal kültürel peyzajların öne çıkan özelliklerini içermesi, geleneksel alan kullanımı ve tarihi doku değerleriyle listede yer alması gerekliliğinin ortaya konulması çalışmayı önemli kılmaktadır.

Anahtar Kelimeler: Kültürel Miras, Selge, Tarım Terasları
In this study, the traditional land use pattern and the agricultural terraces of Selge with thousands of years in terms of World Heritage cultural landscapes and agricultural and rural features in terms of World Heritage cultural landscapes will be examined.

In the study, the heritage sites in the World Heritage List are interpreted in accordance with the selection criteria. According to the criteria determined by UNESCO in terms of traditional agricultural terraces and antique features, which are revealed by the field studies and the source examinations and which are a distinctive feature of the ancient city of Selge, were evaluated. The work of the ancient city of Selge and the traditional agricultural terraces in the World Heritage List includes the prominent characteristics of the rural cultural landscapes, the use of traditional space and the presence of historical texture values.

Keywords: Cultural heritage, Selge, Agricultural terraces

\section{GİRİ̧}

Doğal ve kültürel değerlerin korunması ve tanıtılmasında küresel etkinliklerin ve organizasyonların rolü önemlidir. Özellikle bütün ülkeleri bir çatı altında toplayan Birleşmiş Milletler (BM) ve onun bir alt kuruluşu olan Birleşmiş Milletler Eğitim, Bilim ve Kültür Örgütü (UNESCO) tarafından bu konuda yürütülen faaliyetler, uluslararası alanda büyük bir etkiye sahiptir. Bu faaliyetler arasında 16.11.1972 tarihinde yürürlüğe giren Dünya Doğal ve Kültürel Mirası Koruma Sözleşmesi ayrı bir önem taşımaktadır. Bugüne kadar 177 ülke tarafından imzalanan bu sözleşme çerçevesinde belirli niteliklere sahip kültür ve doğa varlıkları dünya mirası ilân edilmekte ve Dünya Mirası Listesi adı altında yayınlanmaktadır (Akpınar, 2007; UNESCO, 2018a).

Dünya Miras sözleşmesinin kabul edilmesinin ilk yıllarında doğal ve kültürel miras arasındaki denge ile yaşayan toplumlar ve doğal çevresi arasındaki bağlantılar tartışılmaya başlanmıştır. 1992 yılında Dünya Mirası Komitesi kültürel peyzajların, sözleşmenin 1. Maddesinde belirtilen "doğanın ve insanın birleşik çalışmalarını" temsil ettiğini kabul etmiştir. Nitekim kültürel peyzaj yapısı, miras alanlarının yalıtılmış adalar olmadığını ve insanlar, sosyal yapılar ve manzara arasında karşılıklı etkileşim halinde olduğunu göstermektedir. Takip eden yıllarda, dünyanın tüm bölgelerinde Dünya Mirası kültürel peyzajlarını inceleyen birçok bölgesel ve uluslararası tematik uzman toplantısı olmuştur (UNESCO World Heritage Papers, 2009; Taylor, 2011).

\footnotetext{
* Corresponding author. Tel.: ; fax: +0-000-000-0000

E-mail address: silabalta00@gmail.com http://dx.doi.org/10.16950/iujad.504777 Orcid No:
} 
Dünya Mirası Sözleşmesi çerçevesinde "Dünya Mirası Komitesi" adı altında 21 üyeli hükümetler arası bir komite oluşturulmuştur. Sözleşmeye taraf ülkeler, yukarıdaki tanımlara uygun varlıklarını tespit etmek ve belirli aralıklarla üyeleri yenilenen bu komiteye bildirmekle yükümlüdürler. Komite, kendisine bildirilen varlıkları yerinde incelemekte, kriterlere uygun olanları Dünya Mirası Listesi'ne almaktadır. Komite, listeye alınan varlıklarla ilgili gelişmeleri yakından takip etmektedir. Komite, ilgili ülkenin taahhütlerini yerine getirmemesi veya bozulma ve tahrip gibi nedenlerle evrensel niteliğini kaybetmesi durumunda söz konusu varlığı listeden çıkarabilmektedir. Diğer yandan komite, yasal tehditlerden ziyade ikna gücünü ve malî kaynaklarını kullanarak bu alanda ortaya çıkan sorunları çözmeye çalışmaktadır (Akpınar, 2007).

Dünya Mirası Listesi'nde 2018 yılı itibariyle 1092 miras niteliği taşıyan varlık bulunmaktadır. Bunlardan 845'i kültürel miras olarak listede yer almaktadır. UNESCO (2018b) 'ya göre Dünya Miras'ı Listesinde yer almakta olan, 3'ü tehlike altında ve 4'ü iki ülke sınırlarına giren 105 kültürel peyzaj bulunmaktadır. 1992 yılında Komite tarafından kabul edilen Dünya Mirası Kültürel Peyzajları, 2005 yılında ve 2008'de yapılan düzenlemeyle Dünya Mirası kriterlerine dâhil edilmiştir.

Kırsal peyzaj, insanların kentler dışındaki tarım, ormancılık, rekreasyon, ulaşım ve endüstriyel kapsamlı faaliyetleri ile değişime uğramış olan doğal çevrenin görünümüdür. Kırsal peyzaj, bir yandan mevcut ekolojik koşullara, diğer yandan da onu işleyen toplumların geleneklerine göre şekillenmektedir (Dirik, 2005; Akdoğu, 2014'ten). Bu çalışma itibariyle değerlendirilecek alanlar da Dünya Mirası Kültürel Peyzajları arasından kırsal özelliği ile öne çıkan miraslar olacaktır.

Dünya mirası listesindeki mevcut kırsal kültürel peyzajlara bakıldığında farklı ölçeklerde ve niteliklerde birçok alan bulunmaktadır. Bu kategorideki miraslar arasında her bir kırsal alan farklı özellikleriyle öne çıkmaktadır. Örneğin; tarihi yerleşim dokusuyla öne çıkan Grand Pré Peyzajları, Climats Burgonya'nın bağlarında olduğu gibi yerleşim alanı çevresindeki geleneksel üretim şekilleri ile listede yer alan ya da Maymand Kültürel Peyzajları miras alanında olduğu gibi geleneksel yerleşim dokusunun ve mimari özelliklerinin yanında soyut kültürel özellikleri ile de öne çıkan alanlar olduğu görülmektedir.

Türkiye'den, UNESCO Dünya Mirası Listesinde aralarında Troya Antik Kenti, Afrodisias, Hattuşa (Boğazköy), Safranbolu Şehri ve Çatalhöyük Neolitik Kenti gibi alanların yer aldığı toplam 18 miras alanı bulunmaktadır (Tablo 1). Bu alanlardan Göreme Milli Parkı ve Kapadokya'nın Kayalık Alanları ve Hierapolis-Pamukkale hem doğal hem kültürel nitelik taşıyan karma niteliğindeki miraslar olup, geriye kalan 16 varlık kültürel miras kategorisinde bulunan alanlardır. Son olarak 2018 yılında Göbekli Tepe Dünya Mirası Listesine eklenmiştir (UNESCO, 2018a). Türkiye'deki Dünya miras listesinde yer alan kültürel miras alanlarının çoğunlukla tarih öncesi antik döneme ait alanlar olduğu dikkat çekmektedir.

Tablo 1. Türkiye Sınırlarında Yer Alan Dünya Mirası Alanları (WHC, 2018)

Türkiye'deki Miras Alanları

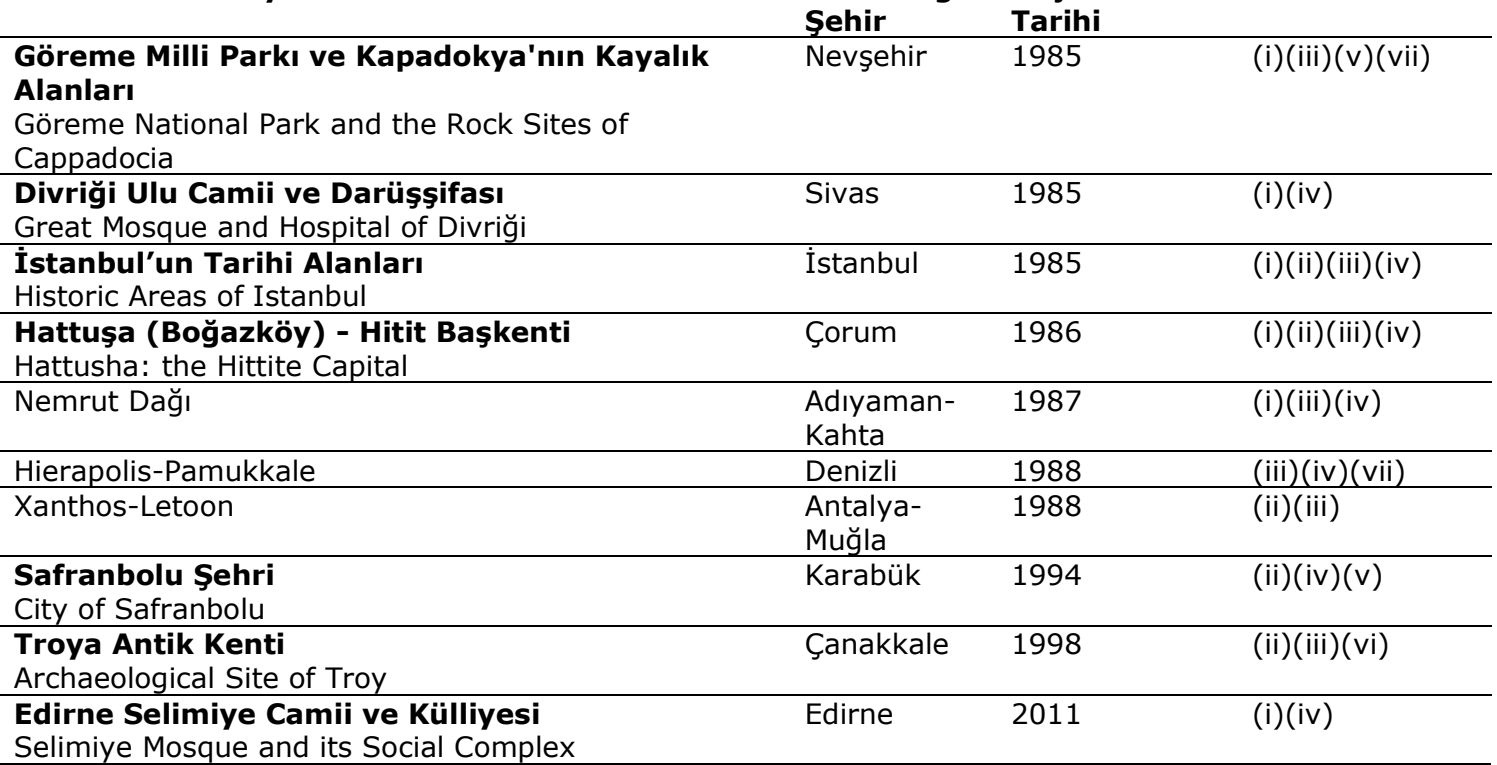
Bulunduğu Seçilme Şehir Tarihi

\section{Kriterler}

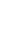




\begin{tabular}{|c|c|c|c|}
\hline $\begin{array}{l}\text { Çatalhöyük Neolitik Kenti } \\
\text { Neolithic Site of Çatalhöyük }\end{array}$ & Konya & 2012 & (iii)(iv) \\
\hline $\begin{array}{l}\text { Bursa ve Cumalıkızık: Osmanlı } \\
\text { İmparatorluğunun Doğuşu } \\
\text { Bursa and Cumalıkızık: the Birth of the Ottoman } \\
\text { Empire }\end{array}$ & Bursa & 2014 & (i)(ii)(iv)(vi) \\
\hline $\begin{array}{l}\text { Bergama Çok Katmanlı Kültürel Peyzaj Alanı } \\
\text { Pergamon and its Multi-Layered Cultural Landscape }\end{array}$ & İzmir & 2014 & (i)(ii)(iii)(iv)(vi) \\
\hline $\begin{array}{l}\text { Diyarbakır Kalesi ve Hevsel Bahçeleri } \\
\text { Kültürel Peyzajları } \\
\text { Diyarbakır Fortress and Hevsel Gardens Cultural } \\
\text { Landscape }\end{array}$ & Diyarbakır & 2015 & (iv) \\
\hline $\begin{array}{l}\text { Efes } \\
\text { Ephesus }\end{array}$ & İzmir & 2015 & (iii)(iv)(vi) \\
\hline $\begin{array}{l}\text { Ani Arkeolojik Alanı } \\
\text { Archaeological Site of Ani }\end{array}$ & Kars & 2016 & (ii)(iii)(iv) \\
\hline Aphrodisias & Aydın & 2017 & (ii)(iii)(iv)(vi) \\
\hline Göbekli Tepe & Şanlıurfa & 2018 & (i)(ii)(iv) \\
\hline
\end{tabular}

Dünya Miras Listesi Kültürel peyzajlarında yer alan kırsal nitelikli örneklere bakıldığında üzüm bağları, geleneksel tarım terasları, otlakları ile önce çıkan alanların listede geniş bir yer tuttuğu görülmektedir. Türkiye bu yönüyle miras listesi içerisindeki kültürel peyzajlar arasında yer alması muhtemel olan ve geleneksel alan kullanımları ile öne çıkan birçok alan olmasına karşın Dünya Mirası Kültürel Peyzajları arasında Türkiye'den yalnızca kültürel peyzajlar içerisinde yer alan tek alanın Diyarbakır Kalesi ve Hevsel Bahçeleri Kültürel Peyzajları olduğu görülmektedir.

Bu çalışmada Dünya Mirası Kültürel Peyzajları açısından tarımsal ve kırsal özellikleri itibariyle binlerce yıldır süregelen alan kullanım deseni ile Selge tarım terasları incelenmiştir. Çalışmada Selge antik kenti ve tarım teraslarının nitelikleri ve özgün değerleri ile Dünya Mirası Listesinde yer alması uygunluğuna dikkat çekilmektedir. Çalışma alanının seçimindeki hedef, ülkemizde yer alan UNESCO Kültürel Miras alanları arasında, Dünya Mirası Listesi Kültürel Peyzajları içerisinde bulunan yalnızca bir alanın olması ve bu listede yer alan miraslarda çoğunlukla görülen geleneksel alan kullanımlarının da yer aldığı bir alanın ülkemizde de bulunduğunu vurgulamaktır.

\section{MATERYAL VE YÖNTEM}

Çalışma materyalini kırsal özellikleri ile öne çıkan UNESCO Dünya Mirası Kültürel Peyzajları arasında yer alan miras alanlarının nitelikleri ve Selge antik kenti ve geleneksel tarım terasları oluşturmaktadır. Çalışma kapsamında Dünya Mirası Kırsal Kültürel Peyzajlar bulunduğu konum, geleneksel alan kullanımları, seçim kriterleri ve tamamlayıcı kriterler üzerinden öne çıkan özellikleri ile değerlendirilmiştir.

Türkiye'de Dünya mirası kültürel peyzajları listesinde yer alan sadece bir alanın olması (Diyarbakır Kalesi ve Hevsel Bahçeleri Kültürel Peyzajları) ve Dünya Mirası Kültürel Peyzajları listesinde yer alan miras alanlarının öne çıkan özellikleri düşünüldüğünde örnek teşkil etmesi muhtemel görülen Selge antik kenti ve geleneksel tarım terasları incelenmiştir.

UNESCO Dünya Miras Listesi Kültürel Peyzajları arasında çalışmada değerlendirilecek kırsal alanların yorumlanması ve tanıtılması aşamasında literatür taramalarından faydalanılmıştır. Selge antik kenti ve geleneksel tarım alanları konusunda gerekli incelemeler sözlü ve yazılı kaynaklar ile arazi incelemeleri vasıtasıyla gerçekleştirilmiştir.

Çalışma iki bölümden oluşmaktadır (Şekil 1). İlk olarak Dünya Mirası Kültürel Peyzajları, kırsal özellikleri kapsamında değerlendirilmiştir. Listede yer alan kültürel peyzajlar arasında kırsal nitelikleriyle öne çıkan alanlar seçilmiş ve seçilme kriterleri ile tamamlayıcı kriterleri doğrultusunda incelenmiştir. İkinci olarak Dünya Miras Listesinde yer almayan fakat evrensel aynı zamanda özgün karakterlere sahip Selge geleneksel tarım terasları, taşımış olduğu doğal ve özellikle de kültürel karakterleri ile UNESCO ve Dünya Miras Komitesi (WHC)'nin miras kriterleri ve tamamlayıcı kriterleri ışığında analiz edilmiştir.

Çalışmada öncelikle Dünya Miras Listesinde yer alan 105 kültürel peyzajdan kırsal nitelik taşıyan 14 adet kırsal kültürel peyzaj örneği incelenmiştir. Bu amaçla Tablo 2'de yer alan miras kriterleri ve seçim kriterlerini bir alt ölçekten destekleyen tamamlayıcı kriterlerden ( 
Tablo 3. kırsal kültürel peyzajlarının alan kullanımları ve seçilme kriterleri açısından yorumlanması aşamasında faydalanılmıştır.

\begin{tabular}{|c|c|}
\hline \multicolumn{2}{|c|}{ Araştırma Alanına ve Konusuna İlişkin Verilerin Toplanması } \\
\hline $\begin{array}{l}\text { Literatür Taraması (Dünya Miras Listesi, Dünya } \\
\text { Mirası Kültürel Peyzajları, Unesco Dünya Miras } \\
\text { Listesi seçim kriterleri) }\end{array}$ & $\begin{array}{l}\text { Selge Antik Kenti'nin doğal peyzaj özellikleri, } \\
\text { kırsal kültürel miras değerleri ile kentte yer alan } \\
\text { tarım teraslarının incelenmesi }\end{array}$ \\
\hline \multicolumn{2}{|c|}{ Dünya Mirası Kültürel Peyzajlarının incelenmesi } \\
\hline \multicolumn{2}{|c|}{$\begin{array}{l}\text { - Dünya Mirası Kültürel Peyzajları arasından kırsal nitelikli peyzajların seçilmesi } \\
\text { - Seçilen kırsal kültürel mirasların seçilme kriterleri ve tamamlayıcı kriterler doğrultusunda } \\
\text { değerlendirilmesi }\end{array}$} \\
\hline \multicolumn{2}{|c|}{$\begin{array}{c}\text { Selge Geleneksel Tarım teraslarının Dünya Mirası Kırsal Kültürel peyzajları } \\
\text { açısından incelenmesi }\end{array}$} \\
\hline \multicolumn{2}{|c|}{ Sonuçlar } \\
\hline
\end{tabular}

Şekil 1. Çalışmanın akışı

Tablo 2. Dünya Mirası kriterleri (UNESCO World Heritage Papers, 2009)

\begin{tabular}{cl}
\hline \multicolumn{1}{c}{ Dünya Mirası Kriterleri } \\
\hline Kriter & \multicolumn{1}{c}{ Dünya Mirası Sözleşmesinin Uygulanmasına Yönelik Rehberlerden Özet Kriter } \\
(i) & $\begin{array}{l}\text { Dahi sayılabilecek bir sanatçının eşsiz bir sanat eserini veya şaheserini temsil } \\
\text { etmek, }\end{array}$ \\
\hline (ii) & $\begin{array}{l}\text { Mimari, anıtsal sanatlar veya şehir planlama ve peyzaj tasarımı alanlarında } \\
\text { gelişme sağlanmasında etkisi büyük olmuş, dünyanın kültürel bir bölgesinde bir } \\
\text { döneme damga vurmuş olmak, }\end{array}$ \\
\hline (iii) & $\begin{array}{l}\text { Günümüzde yaşamayan bir medeniyetin veya kültürel geleneğin eşsiz ya da } \\
\text { istisnai bir kanıtını taşımak; }\end{array}$ \\
\hline (iv) & $\begin{array}{l}\text { İnsanlık tarihinde önemli bir aşamayı veya aşamaları gösteren bir yapı biçiminin } \\
\text { veya mimari bileşim veya peyzajın olağanüstü örneği olmak, }\end{array}$ \\
\hline (v) & $\begin{array}{l}\text { Bir kültürü temsil eden geleneksel insan yerleşimi veya toprak kullanımının } \\
\text { önemli bir örneği olmak; özellikle herhangi bir etki tarafından telafisi mümkün } \\
\text { olmayan bir bozulma tehdidi altında olmak, }\end{array}$ \\
\hline Olaylar veya yaşayan geleneklerle, fikirlerle ya da inançlarla doğrudan veya \\
somut bir şekilde bağlantılı olan olağanüstü evrensel değere sahip sanatsal veya \\
yazılı eserler,
\end{tabular}

Tablo 3. Dünya Mirası Kültürel Peyzajları için Tamamlayıcı Kriterler (UNESCO, 2018b)

\begin{tabular}{l|l}
\hline Kültürel & Doğal \\
\hline B: Yapılar, çoğunlukla büyük yapılar, mevcut alan & Jf: Orman, ağaçlandırma Alanları \\
C: Süregelen yaşam şekilleri/ alan kullanımlarının & M: Dağın veya Dağların peyzajın \\
peyzajın önemli bir parçası olduğu alanlar & ayrılmaz bir parçası olan alanları \\
F: Çiftçilik/Tarımsal aktivitelerin geçmişte veya & N: Doğa Parkı'nın içinde barındıran veya \\
bugün temel eleman olduğu doğal peyzaj alanları & Doğa Park'ı olan peyzaj alanları \\
G: Dekoratif Park(lar)/Bahçe(ler)nin temel & W: Suyun peyzajın ayrılmaz bir parçası \\
eleman olduğu alanlar & olduğualanları \\
I: Endüstri alanları & WI: Göl veya Göllerin peyzajın ayrılmaz \\
\hline
\end{tabular}




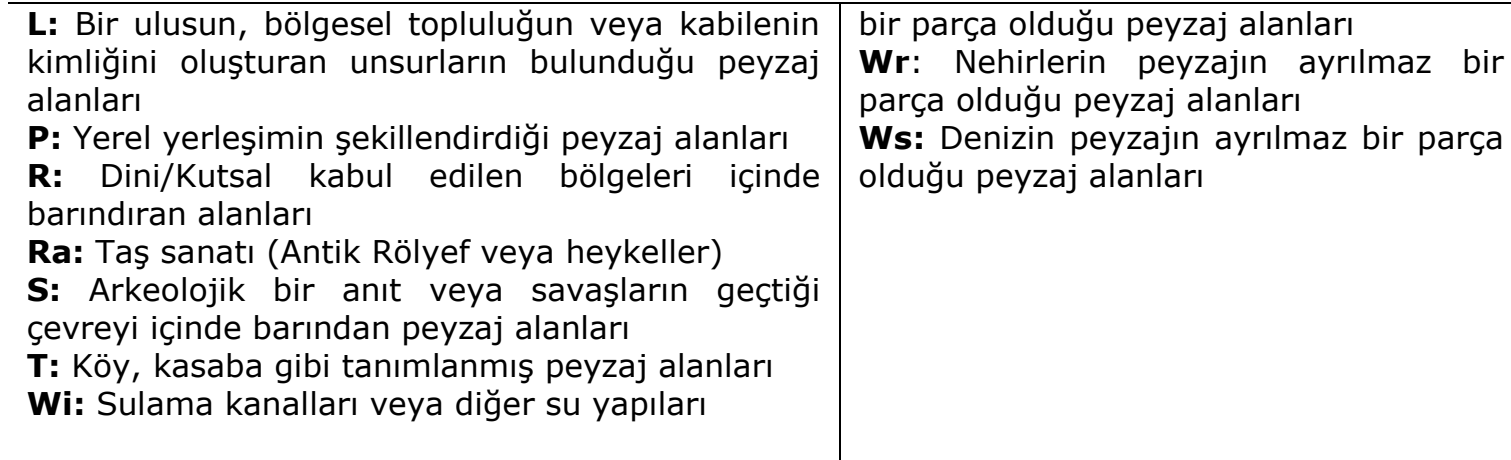

Çalışma alanı olan Selge Antik Kenti ve Tarım Terasları Antalya'nın Manavgat ilçesine bağlı Toros Dağları'nın 1000-1250 m yükseklik aralığında yer alan bir dağ sırtı yerleşimidir (Şekil 2). Selge'nin tarihi M.Ö. 1200 yılına dayanmaktadır. Selge dağ zirveleri ile çevrili verimli bir havza üzerine inşa edilmiştir (Atik ve Altuntaş, 2011). Selge'de Altınkaya kırsal yerleşimi içindeki ve çevresindeki geleneksel tarım terasları binlerce yıldan beri yöre halkı tarafından nadas yöntemiyle geleneksel olarak halen kullanılmaktadır.
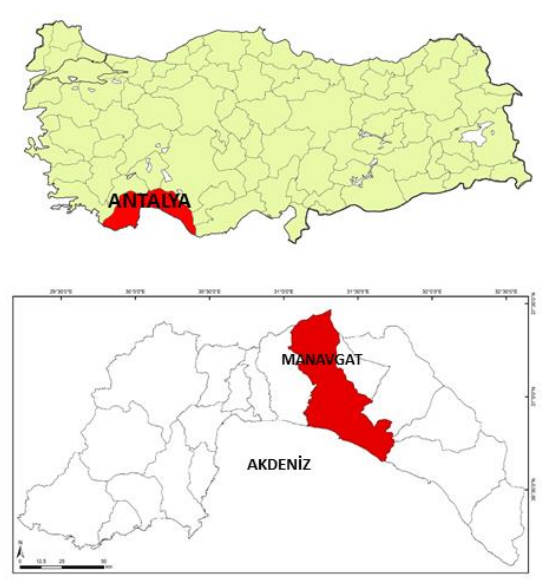

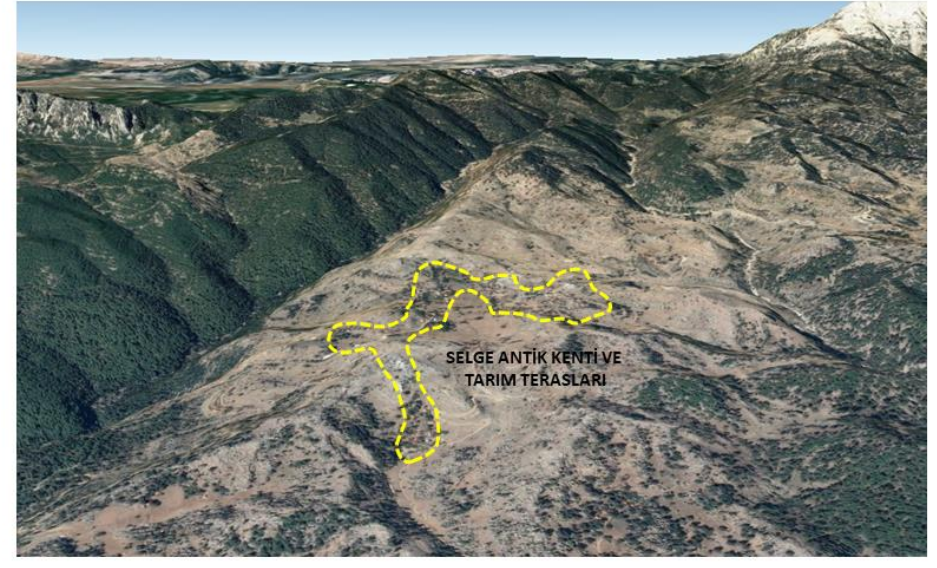

Şekil 2. Çalışma Alanı

Çalışma kapsamında Selge antik kenti ve geleneksel tarım teraslarının bulunduğu Altınkaya köyünde arazi çalışmaları yapılmıştır. Arazi incelemeleri boyunca alanın doğal ve kültürel özellikleri açısından gözlemler yapılmış olup, sözlü görüşmeler ile Selge geleneksel tarım teraslarının kullanımı ve yerel yaşantı hakkında da bilgi toplanmıştır.

\section{BULGULAR}

\subsection{Dünya Mirası Kırsal Kültürel Peyzajları}

Kültürel miras denildiğinde çoğunlukla mimari miras, yapılar, köprü ve kent gibi yapısal unsurların öne çıktığı alanların akla geldiği görülmektedir. Diğer yandan geleneksel alan kullanım modelleri, ürün deseni gibi kırsal karakterlerin de miras niteliği taşıdığı listede yer alan örneklerde oldukça sık görülmektedir.

Çalışma kapsamında Dünya Mirası Kültürel Peyzajları listesi içinde yer alan miraslar arasından Selge antik kenti ve tarım terasları ile ilişkilendirmeyi kuvvetlendirmek adına, kırsal ve tarımsal nitelikli miras alanları seçilmiştir (Tablo 4). Seçilen kırsal kültürel miras alanları arasında üretim tiplerinin ve yetiştirilecek ürün ile ortaya çıkan arazi kullanımlarının kattığı değer göze çarpmaktadır. Örneğin; Wachau Kültürel Peyzajları, Saint-Emilion Bölgesi, Tokaj-Hegyalja Şarap Bölgesi ya da Lavaux Üzüm Bağları gibi dünya mirası kültürel peyzajları arasında yer alan kırsal nitelikli alanlarda alan kullanım tipi olarak üzüm bağlarının yer aldığı görülmektedir. Honghe Hani Pirinç Terasları Kültürel Peyzajları, pirinç üretimi ve buna bağlı olarak oluşturulan tarım teraslarının eşsiz görüntüleri ile listede yer almaktadır (Şekil 3). Üretim faaliyetlerinin etkisi, tarım alanları çevresinde bulunan yerel halkın yaşadığı ve geleneksel mimari örneklerin görülebildiği alanlar ile desteklenmektedir. Dünya Mirası 
Kırsal Kültürel Peyzajları, soyut ve somut birçok miras değerini barındırmasıyla geleneksel yaşam hakkında bilgiler vermektedir.

Dünya mirası kırsal kültürel peyzajları incelendiğinde seçim kriterleri açısından Dünya Miras Listesinde yer alan kültürel peyzajlarda çoğunlukta (iii), (iv) ve (v) kriterlerinin öne çıktığı görülmektedir. Görülen bu kriterlerin miras listesindeki tanımlamasına bakıldığında bir medeniyet ya da kültürel geleneğin varlığına dair izler, tarih içerisinde yer almış önemli yapı biçimi, mimari bileşim ya da peyzajın bir örneğini taşımak ve geleneksel insan yerleşimi ile toprak kullanımının önemli bir örneği olmak tanımlamaları görülmektedir. Değerlendirilen Dünya Mirası Kırsal Kültürel Peyzajları arasında özellikle tarımsal faaliyetleri ile geleneksel yerleşim alanları kriterleri karşılama yönünden etkili olmuştur (Tablo 4). Bu yönüyle değerlendirmeye alınan Selge antik kenti ve tarım teraslarının bu kriterleri karşıladığı göze çarpmaktadır.

Tablo 4. Dünya Mirası Kırsal Kültürel Peyzajları

\begin{tabular}{|c|c|c|c|c|}
\hline Kırsal Kültürel Peyzajlar & $\begin{array}{l}\text { Bulunduğu kıta } \\
\text { ve ülke }\end{array}$ & $\begin{array}{l}\text { Seçilme } \\
\text { Tarihi }\end{array}$ & Kriterler & $\begin{array}{l}\text { Öne Çıkan Kırsal } \\
\text { Tarımsal Alan } \\
\text { Kullanımları }\end{array}$ \\
\hline $\begin{array}{l}\text { Wachau Kültürel Peyzajları } \\
\text { Wachau Cultural Landscape }\end{array}$ & $\begin{array}{l}\text { Avrupa- } \\
\text { Avusturya }\end{array}$ & 2000 & (ii)(iv) & $\begin{array}{l}\text { Üzüm Bağları, Şarap } \\
\text { Üretimi, Kırsal Yerleşim } \\
\text { Alanları }\end{array}$ \\
\hline $\begin{array}{l}\text { Grand Pré Peyzajları } \\
\text { Landscape of Grand Pré }\end{array}$ & $\begin{array}{l}\text { Kuzey Amerika- } \\
\text { Kanada }\end{array}$ & 2012 & $(v)(v i)$ & Tarım alanları \\
\hline $\begin{array}{l}\text { Honghe Hani Pirinç Terasları Kültürel } \\
\text { Peyzajları } \\
\text { Cultural Landscape of Honghe Hani Rice } \\
\text { Terraces }\end{array}$ & Asya-Çin & 2013 & $(\mathrm{iii})(\mathrm{v})$ & Pirinç Terasları \\
\hline $\begin{array}{l}\text { Kolombiya Kahve Yetiştirme Alanları } \\
\text { Coffee Cultural Landscape of Colombia }\end{array}$ & $\begin{array}{l}\text { Güney Amerika- } \\
\text { Kolombiya }\end{array}$ & 2011 & $(\mathrm{v})(\mathrm{vi})$ & Kahve Bahçeleri \\
\hline $\begin{array}{l}\text { Vinales Vadisi } \\
\text { Viñales Valley }\end{array}$ & $\begin{array}{l}\text { Kuzey Amerika- } \\
\text { Küba }\end{array}$ & 1999 & (iv) & Tütün Bahçeleri \\
\hline $\begin{array}{l}\text { Kujataa Arktik-altı Tarım Alanları } \\
\text { Kujataa Greenland: Norse and Inuit } \\
\text { Farming at the Edge of the Ice Cap }\end{array}$ & $\begin{array}{l}\text { Avrupa- } \\
\text { Danimarka }\end{array}$ & 2017 & (v) & Tarım Alanları \\
\hline $\begin{array}{l}\text { Saint-Emilion'un Bölgesi } \\
\text { Jurisdiction of Saint-Emilion }\end{array}$ & Avrupa- Fransa & 1999 & (iii)(iv) & $\begin{array}{l}\text { Üzüm Bağları, Yerleşim } \\
\text { Alanları }\end{array}$ \\
\hline $\begin{array}{l}\text { Climats, Burgonya'nın bağları } \\
\text { The Climats, terroirs of Burgund }\end{array}$ & Avrupa-Fransa & 2015 & $(\mathrm{iii})(\mathrm{v})$ & $\begin{array}{l}\text { Üzüm Bağları, Kırsal } \\
\text { Yerleşim Alanları }\end{array}$ \\
\hline $\begin{array}{l}\text { Tokaj-Hegyalja Şarap Bölgesi } \\
\text { Tokaj Wine Region Historic Cultural } \\
\text { Landscape } \\
\text { Criteria }\end{array}$ & $\begin{array}{l}\text { Avrupa- } \\
\text { Macaristan }\end{array}$ & 2002 & $(\mathrm{iii})(\mathrm{v})$ & $\begin{array}{l}\text { Üzüm Bağları, Kırsal } \\
\text { Yerleşim Alanları }\end{array}$ \\
\hline Val d'Orcia & Avrupa-İtalya & 2004 & (iv)(vi) & $\begin{array}{l}\text { Tarım Alanları, Kırsal } \\
\text { Yerleşim Alanları }\end{array}$ \\
\hline $\begin{array}{l}\text { Causses ve Cévennes, Akdeniz agro- } \\
\text { pastoral Kültürel Peyzajı } \\
\text { The Causses and the Cévennes, } \\
\text { Mediterranean agro-pastoral Cultural } \\
\text { Landscape }\end{array}$ & Avrupa-Fransa & 2011 & $(\mathrm{iii})(\mathrm{v})$ & $\begin{array}{l}\text { Kırsal Yerleşim alanları, } \\
\text { Meralar, } \\
\text { Tarım alanları }\end{array}$ \\
\hline $\begin{array}{l}\text { Maymand Kültürel Peyzajları } \\
\text { Cultural Landscape of Maymand }\end{array}$ & Asya-İran & 2015 & (v) & $\begin{array}{l}\text { Hayvancılık, } \\
\text { Kırsal Yerleşim Alanları }\end{array}$ \\
\hline $\begin{array}{l}\text { Lavaux Üzüm Terasları } \\
\text { Lavaux, Vineyard Terraces }\end{array}$ & Avrupa-İsviçre & 2007 & (iii)(iv) (v) & $\begin{array}{l}\text { Üzüm Bağları, Kırsal } \\
\text { Yerleşim Alanları }\end{array}$ \\
\hline
\end{tabular}

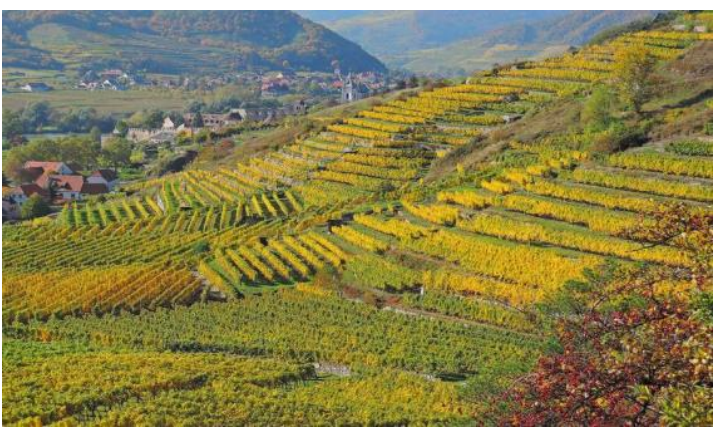

(a)

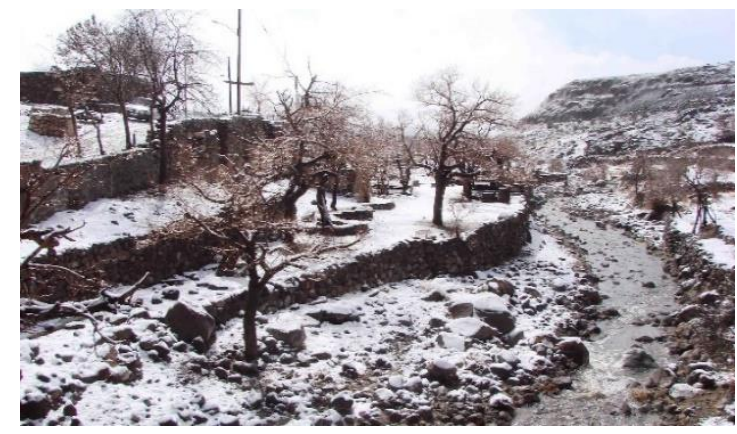

(b) 




(c)

Şekil 3. Dünya Mirası kültürel peyzajlarından örnekler; (a) Wachau Kültürel Peyzajları (Weltkulturerbe Wachau, 2018); (b) Maymand Kültürel Peyzajları (Maymand, 2018); (c) Val d'Orcia (Val d'Orcia, 2018)

\subsection{Selge Antik Kenti ve Tarım Teraslarının Kırsal Kültürel Miras Değerleri}

Toros Dağları'nın ortalama 950 m yükseklikte yer alan Selge kenti kalıntıları ve tarım terasları, kırsal yerleşimi içerisinde yer almaktadır (Şekil 4). Selge antik kenti içinde bulunduğu Altınkaya Köyü (Zerk) ile birlikte Gayrimenkul Eski Eserler ve Anıtlar Yüksek Kurulunun 15.11.1978 gün ve A-1108 kararı ile "I. Derece Arkeolojik Sit Alanı" olarak ilan

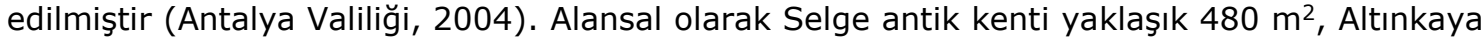
(Zerk) Köyü yaklaşık $330 \mathrm{~m}^{2}$ ve Selge geleneksel tarım terasları ise $1400 \mathrm{~m}^{2}$ alan kaplamaktadır (Şekil 4).



Şekil 4. Altınkaya Köyü ve Selge Antik Kenti (Orijinal, 2018)

Selge antik kentinde bilimsel arkeolojik kazı çalışmalarının azlığı kentin kronolojik bir tarihi çıkarılmasını mümkün kılmamaktadır. Ancak diğer antik şehir devletlerinin yazıtlarında ve bölge ile ilgili yapılan çalışmalarda Selge'den bahsediliyor olması kentin kuruluşu hakkında fikir verebilmektedir. Hitit yazıtlarında bölgenin Pithassa (Psidia) bölgesinde bulunduğu ve kent halkının kökeninin M.Ö. 13. Yüzyılda kuzey doğu Avrupa steplerinden Akdeniz'e göçen Nordik kavimlerden Pithassalılar olduğu anlaşılmaktadır (Kunar, 1995). Von Lanckoronski (1892), Strabon'un, kentin ilk kurucularının Spartalı Lakedaimonlardan Kalkhas halkı olduğunu ifade ettiğini belirtmiştir (Tablo 5). Birçok uygarlığa yaptığı ev sahipliğinden sonra, M.S 13.yy'da Selge Türkler ile el değiştirmiştir ve antik harabeler arasındaki köy, 200 yıl kadar önce göçebe olarak gelen Yörükler tarafından Selge'den esinlenerek Zerk adıyla kurulmuştur (Antalya İl Kültür ve Turizm Müdürlüğü, 2018). M.Ö 1. yy'da Selge ve çevresinde Pontus, Galatia ve sonrasında tekrar Roma egemenlikleri görüldüğü de bilinmektedir (Büyükyıldırım, 1991).

Tablo 5. Selge antik kentinde yaşayan uygarlıklar (Kunar, 1995; Antalya Valiliği, 2004; Bean, 1999; Strabon, 2009; Antalya İl Kültür ve Turizm Müdürlüğü, 2018) 


\begin{tabular}{ll}
\hline Tarih & Yaşayan uygarlıklar \\
\hline- & Lakedaimon/ Kalkhas halkı \\
\hline M.Ö. 13. yy & Pithassalılar \\
\hline M.Ö. 1200- 1150 & Dorlar \\
\hline M.Ö 7. yy başları & Rodoslu Kolonistler \\
\hline- & Romalılar \\
\hline MS. 13. yy & Türkler \\
\hline
\end{tabular}

Selge kenti, Bizans Döneminde Aspendos'a bağlanmıştır ve deniz ticaretinin bu dönemde geliştiği söylenmektedir. Bu dönemden sora kıyı kentlerinin zenginleşmesi ile kıyılara göçler başlamıştır (Kunar, 1995). Çoğunlukla Roma dönemine tarihlendirilen Selge harabeleri, özellikle M.S. ikinci yüzyılda Selge'nin ne kadar zengin ve güçlü bir şehir olduğunu göstermesi açısından önemlidir (Antalya İl Kültür ve Turizm Müdürlüğü, 2018). Bugünkü şehir kalıntıları çoğunlukla surlardan ve akropolisten oluşmaktadır. Günümüze ulaşan en sağlam yapı M.S. 3 yüzyılda restore edilen tiyatrodur. Köprüçay Irmağı üzerinde ve onu takip eden yol güzergâhında çok sayıda antik yapı bulunmaktadır (Nolle, 2015; Antalya İl Kültür ve Turizm Müdürlüğü, 2018).

Selge antik kenti Akdeniz-Eğirdir üzerinden geçen İç Anadolu'ya bağlanan Aspendos-SelgePednelisos- Adada- Aprotari antik yollarının geçtiği güzergah üzerinde bulunmaktadır (Kunar, 1995). Aynı zamanda Olukköprü'den Selge'ye çıkan bir antik gö̧ yolu da bulunmaktadır (Büyükyıldırım, 1991).

Tarımsal açıdan Kunar (1995) Selgeliler'in geçmişte üzüm, şarap, hayvancılık ve kerestecilik ile uğraştığını belirtmektedir. Bugün bölgedeki az sayıdaki hayvancılık yanında antik dönemden günümüze ulaşmış Selge geleneksel tarım terasları nadas yoluyla halen kullanılmakta ve yöre halkı için önemli bir geçim kaynağı sunmaktadır. Coğrafyacı Strabon (2009) tarım arazilerinin yanında, Selge etrafında yer alan Servi (Cupressus sempervirens) ormanlarının ticaret amaçlı kullanılması ile seyrekleşen alanlara dikilen zeytin ağaçları görüldüğünü belirtmiştir. Fazla sayıdaki bu zeytin ağaçları bazı noktalarda düzgün sıralanmış bir şekilde göze çarpmaktadır. O dönemde şehrin çevresinde ne kadar alçak konumlu yer varsa hemen hemen hepsinin zeytinliklerle kaplı olduğu bildirilmektedir. Strabon, zeytinliklerin yanında bereketli üzüm bağlarından da bahsetmektedir (Nolle, 2015). Strabon'dan sonraki dönemlerde Selge'yi ziyaret eden araştırmacılardan Von Lanckoronski (1892), Selge'de yetiştirilen tahıl, mısır, üzüm, ceviz ve kestaneden bahsetmiş; ancak Strabon'un tarif ettiği kadar yoğun bir zeytinliğe rastlamadığını ifade etmiştir. Bu da Strabon'un betimlediği yoğun zeytinliklerin eskiden kalma bir miras olduğunu göstermektedir.

Selge'nin tarihi hakkında birçok bilginin edinilmesini oluşturan ögelerden biri Selge'nin bastırdığı gümüş paralardır. Yetiştirilen zeytin ağaçları, Selge etrafındaki orman varlığı, yetiştirilen diğer ürünler ve ülkelerle ticari ilişkileri hakkında birçok bilgi gümüş sikkeler üzerinden yorumlanabilmektedir. Tüm bunların yanında Selge'de yer alan tarım terasları ve üretime verdikleri değer de bu gümüş sikkeler üzerinde görülmektedir. Nümismatik açıdan bakıldığında antik dönem Selge paraları üzerinde betimlenen ekim yapan ve tohum eken insan figürü tarım teraslarındaki üretim şeklini günümüze yansıtmaktadır. Aynı zamanda güreş yapan insan figürleri antik dönem toplum yaşantısı ve tarımsal faaliyetlerin bu geleneksel yaşamdaki yeri konusunda fikir vermektedir (Şekil 5). Selge ve Manavgat yöresi bugün halen ülke çapındaki ulusal ve uluslararası yarışmalarda ödül kazanan güreş̧̧ileri ile öne çıkmaktadır. 


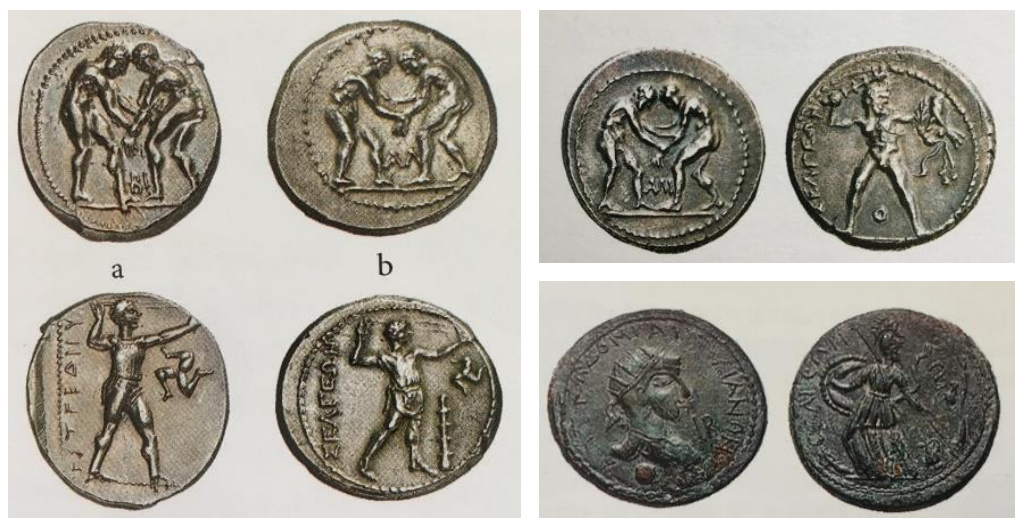

Şekil 5. Selge paraları (Nolle, 2015)

Selge şehri coğrafi olarak karstik bir çukurlukta yer almaktadır ve bu çukurluğu dolduran humuslu toprak sayesinde bugün hala devam eden tarla ve bahçe ürünleri yetiştiriciliği yöre ekonomisine önemli bir katkı sunmaktadır. Selge'deki eğimli arazi yapısı, yükseltilerin teraslanarak işlenebilir hale getirilmesini ve taş teraslar arasına bahçe ve tarlalarının tesisini zorunlu kılmıştır. Yamaçlarda yapılan teraslar sayesinde tarım arazileri genişletilmiştir (Kunar, 1995; Nolle, 2015) (Şekil 6).
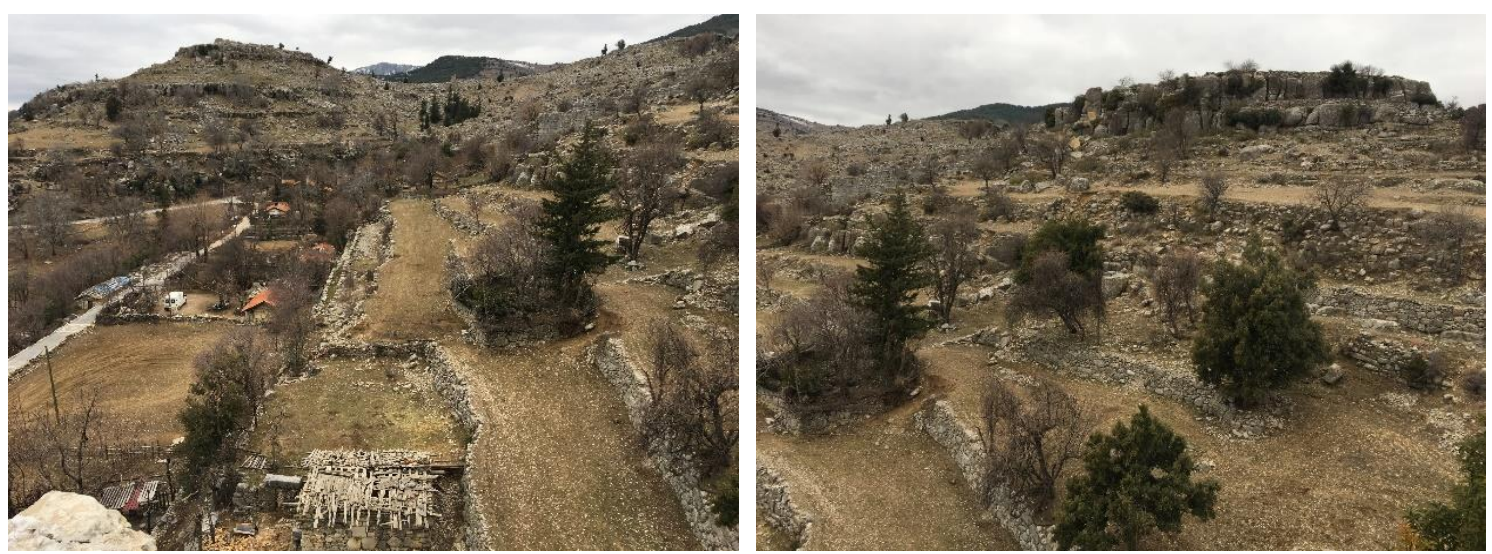

Şekil 6. Selge Geleneksel Tarım Terasları (Orijinal, 2018)

Selge aynı zamanda bir çok endemik canlı türünü barındıran ormanları, doğa harikası bir jeolojik oluşuma sahip kanyonları, peyzaj değeri yüksek bir rekreasyon alanı olan Köprülü Kanyon Milli Parkı sınırları içinde kalmaktadır. En parlak zamanını Roma Dönemi'nde almış, Strabon'a göre nüfusun 20.000 kişiye çıktığı zamanlar olmuştur (Antalya İl Kültür ve Turizm Müdürlüğü, 2018).

Günümüzde Selge ve çevresinde, Türkiye'nin en büyük kanyonlarından 'Köprülü Kanyon' olarak adlandırılan kanyon ve yine aynı adı taşıyan milli parkın yer alması bölgenin yüksek peyzaj değerine sahip olduğunu göstermektedir. Selge'yi çevreleyen ormanlar arasında göze ilk çarpan vadi içlerindeki sık ve gür servi (Cupressus sempervirens) ormanlarının varlığıdır. Aynı zamanda 2000 metre ve üzerindeki yükseltilerde yoğun Sedir (Cedrus libani) ormanları görülmektedir. Kayacık (1966)'ın ifade ettiği üzere, Köprülü Kanyon Milli Parkı içerisinde görülen bu servi ormanları, Toros dağlarında ve onun da ötesinde tüm Türkiye'de doğal niteliğini korumuş tek ormandır. Bu orman bölgenin Milli Park statüsü kazanmasının nedenlerinden biri olarak görülmektedir. Köprülü Kanyon Milli Parkı'nda yer alan başlıca peyzaj özellikleri; kanyonlar ve Roma köprüsü, doğal servi ormanı ve eski sedir ormanı, Adamkayalar kaya oluşumları ve Selge Antik Kentidir (Atik ve Altuntaş, 2011; Nolle, 2015). 
Selge şu anda eski kent yerleşiminin olduğu alanda varlığını sürdürmektedir. Kentin antik kalıntıları arasında en belirgin olarak görülen tiyatro ve hemen yanındaki yerleşim alanıgörsel peyzaj değerleri açısından çeşitlilik göstermektedir (Şekil 7).

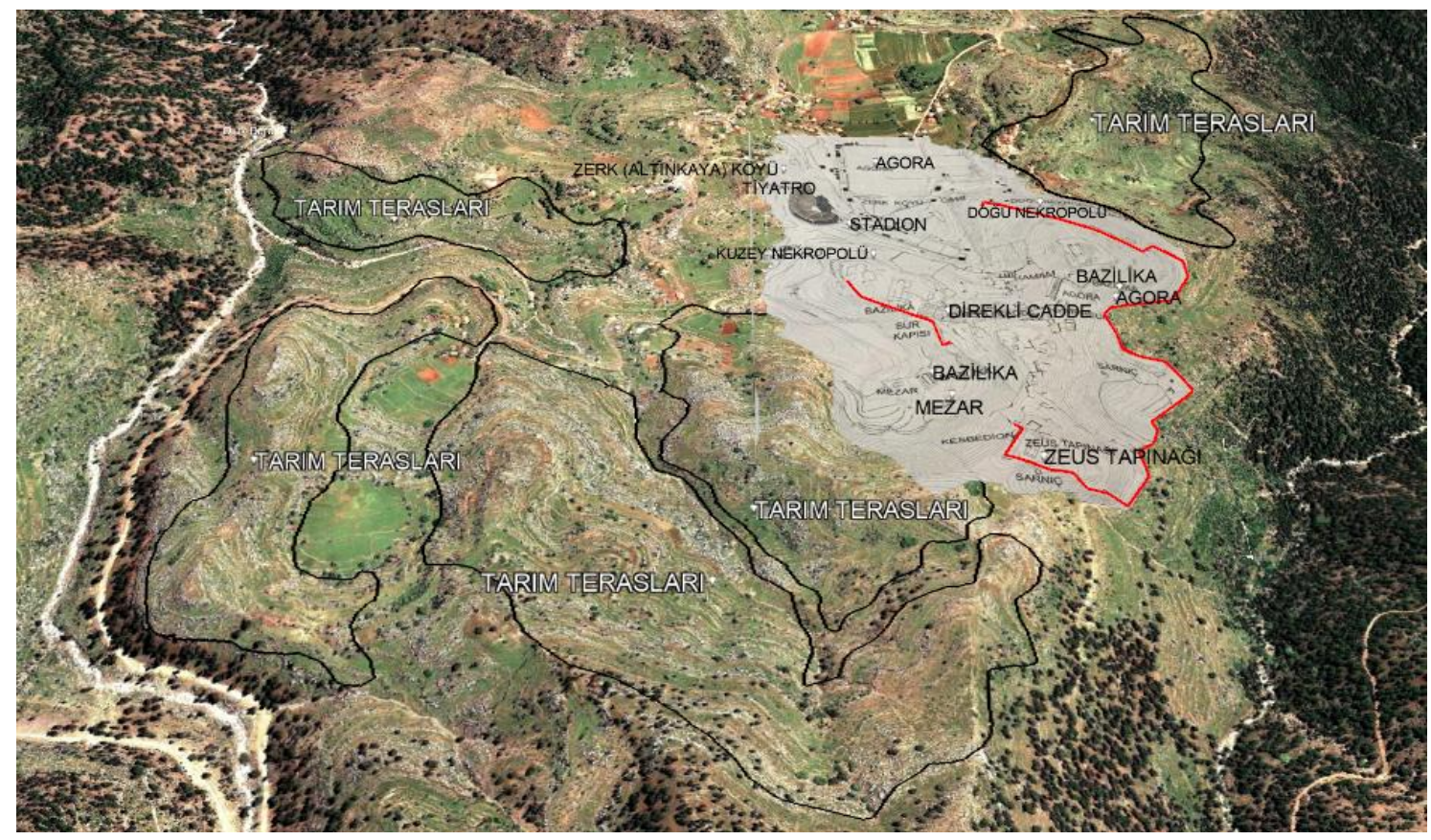

Şekil 7. Selge Antik kenti eski yerleşimi ve geleneksel tarım terasları

\subsection{Selge Antik Kenti ve Tarım Teraslarının Dünya Mirası Kriterleri Açısından Değerlendirilmesi}

Türkiye'den seçilmiş alanlar arasında kırsal nitelikte Dünya Mirası Kültürel Peyzaj listesinde yer alan bir alan bulunmamakla birlikte Selge Antik kenti içerisinde yer alan tarihi alanları, geleneksel tarım terasları ve somut olmayan kültürel değerleri ile Dünya Mirası Kırsal Kültürel Peyzajlarında yoğunlukta olan (iii), (iv) ve (v) kriterleri ve bu kriterler dışında Atik ve Altuntaş (2011)'ın Selge Antik Kenti için tanımladığı (i), (ii), (vii), (viii), (x) kriterler arasından kültürel nitelikli olan (i) ve (ii) kriterleri ile kültürel özellikleri tanımlayan $F$ (Çiftçilik/Tarımsal aktivitelerin geçmişte veya bugün temel eleman olduğu doğal peyzajlar), C (Süregelen yaşam şekilleri/ alan kullanımlarının peyzajın önemli bir parçası olan alanlar), P (Yerel yerleşimin şekillendirdiği peyzaj alanlar) tamamlayıcı kriterleri bakımından değerlendirilmiştir.

Buna göre Selge Antik kenti ve geleneksel tarım terasları Dünya Mirası Kriterlerini;

- Şehri 2000 yıldan fazla bir süredir çevreleyen doğal taş duvarlar üzerine oturtulmuş tarım terasları (i);

- Erişimi zor, çok dağlık bir arazide kurulan ve halen yerleşim yapısının devamlılığını sürdürmesi (ii);

- Bölgenin tarım tarihi, geleneksel alan kullanımları ve bu kullanımlara bağlı yaşam şekli hakkında özgün bilgiler sunması (iii);

- Sahip olduğu kent kalıntıları ve kullanılan yapım teknikler ve çözümleri itibariyle dönemi hakkında değerli bilgileri yansıtması (iv);

- Taş duvarlı tarım teraslarının kente kültürel ve ekolojik değer katması ile eski zamanlardan bu yana geleneksel arazi kullanımını devam ettirmesi (v) gibi özellikleri ile karşılamaktadır.

Dünya Mirası seçim kriterlerini özelde destekleyen tamamlayıcı kriterler arasından özellikle geleneksel taş duvar ile örülmüş tarım terasları ve zorlu arazi yapısında varlığını sürdüren antik kentin üretimi sağlamak açısından araziyi değerlendirme şekli ile topoğrafik yapıya uygun olarak yamaçlara oturtulmuş tarım terasları ve tarımsal üretim, çiftçilik (F- Farming), 
(C- Convention) ve yöre halkının hayatta kalma çabası (P- People) kriterlerini karşılamaktadır.

\section{TARTIŞMA VE SONUÇ}

Ülkemizde birçok dünya mirası kültürel peyzajları listesine dahil olmaya değer alan bulunmaktadır. Selge antik kenti de tarımsal nitelikleri ve geçmiş ile günümüz arasında kurduğu köprü niteliği ile bu bağlamda önemli görülmüştür.

Selge için Dünya Mirası Listesindeki adaylığı açısından çalışma kapsamında yapılan literatür taramalarında, Kap Yücel ve Salt (2018) tarafından yapılan Kültür ve Turizm Bakanlığı'nın yapmış olduğu başvuru ile, 15 Nisan 2014 tarihinde "UNESCO Dünya Miras Geçici Listesine kabul edilen Bursa İznik örneği üzerinden kültürel peyzajların korunması ve yönetilmesini irdelemek için alanda meydana gelene değişimi tespit etmek üzere yapılan çalışmadan kültürel peyzaj tanımı ve Dünya Mirası Kültürel Peyzaj'larının irdelenmesi aşamasında yararlanılmıştır. Akpınar (2007)'ın Türkiye'nin Dünya Miras Listesindeki yerini incelediği ve Gelibolu Yarımadası Tarihî Millî Parkı'nın yeni bir aday önerisi olarak getirildiği çalışma, Dünya Miras Listesi'ne aday gösterilecek bir alan için yapılan incelemeler ve izlenilen sürece yönelik bilgi vermesi yönüyle; Yalçın Coşkun (2009)'un UNESCO Dünya Miras Listesinde o dönem Türkiye'den kültürel peyzaj listesinde olan bir alan bulunmayışından yola çıkarak kültürel peyzajları ve özgün yöresel mimari ile Muğla Çomakdağ köyünü liste adaylığı bakımından incelediği çalışmalar değerlendirmeye alınmıştır.

Mevcut çalışmalar göz önünde bulundurulduğunda odaklanılan kültürel peyzaj kavramını 'kırsal' açıdan değerlendirerek Selge antik kenti ve geleneksel tarım teraslarının daha iyi anlaşılabileceği ve yorumlanabileceği düşünülmüştür. Bu amaçla alanın özellikleri ve öne çıkan tarım teraslarını daha iyi ifade eden niteliklerin kültürel olması ile Selge antik kenti ve geleneksel tarım terasları Dünya Mirası seçim kriterleri arasından özellikle kültürel nitelikli kriterleri ve tamamlayıcı kriterleri açısından değerlendirilmiştir (Tablo 6).

Dünya Mirası Listesi Kırsal Kültürel Peyzajları arasında seçili olan alanlar arasında tarımsal faaliyetleri, geleneksel üretim şekilleri ve bu alanlar arasında yer alan yerleşim alanları ile ortak niteliklere sahip olan Selge geleneksel tarım alanları Dünya Mirası kültürel peyzajları listesinde yer alma potansiyeline sahiptir.

Tablo 6. Selge Antik Kenti ve Tarım Terasları özellikleri ve seçim kriterleri

\section{Selge Antik Kenti ve Tarım Terasları}

Antalya İli Manavgat ilçesine bağlı Altınkaya (Zerk) köyünde bulunan ve geleneksel tarım teraslarıyla öne çıkan, hala varlığını sürdüren tarihi yerleşim

DOĞAL ÖZELLİKLERİ

Konum

Yerleşim Formu

\section{KÜLTÜREL ÖZELLLİKLERİ}

Baskın Arazi Kullanımı

Mimari Özellikleri

Tarihsel Özellikleri
800- 1200 m yükseklikleri arasında yer alan bir dağ sırtı yerleşimidir. Konumu itibariyle organik yerleşim formu görülmektedir.
Teraslara konumlandırılmış tarla ve konut bahçeler Geleneksel yerleşim alanları

Doğal yığma taş duvarlı konutlar çoğunlukla tek ya da iki katıdır.

- Kuruluşu M.Ö. 13. yy'a dayanan ve tarihi boyunca birçok uygarlığa ev sahipliği yapmış, şu an Altınkaya (Zerk) köyü yerleşimi içerisinde bulunan Antik bir kenttir.

- Kentin karakteristik özellikleri arasında olan geleneksel tarım terasları görülmektedir.

Selge, tarihinde üzüm bağları, zeytin ve kerestecilik için kullanılan Sedirlerin yanında ekonomik faaliyetlerini taş teraslarda yaptıkları tarım ile de sürdürmüştür.

- Selge Antik kentine ait kalıntılar ve hala varlığını sürdüren antik tiyatro köy yerleşimi içerisinde yer almaktadır.

- Geleneksel tarım terasları bugün de kullanılmakta olup, nadas yöntemiyle üretim için değerlendirilmektedir.

Yerleşim içerisinden geçen tarihi rotalar ve göc yolları bulunmaktadır.

Tarihlerinde yaptıkları ticari faaliyetleri, üretim şekillerini ve bitki örtüsü hakkında bilgi vermesi sebebiyle Selge'nin gümüş sikkeleri önemlidir. 


\section{DOĞAL ÇEVREDEN ETKİLEȘíM}

Selge etrafında yer alan Servi ormanları ve zeytin ağaçları hem doğal hem de ticari değeri açısından önemli görülmektedir.

Arazi koşullarının zorluğu ve topoğrafyanın etkisiyle bitkisel üretim faaliyetleri doğal taşlardan yapılmış tarım terasları ile gerçekleştirilmektedir.

\section{UYGUNLUĞU BULUNAN KÜLTÜREL KRİTERLER}

Seçim Kriterleri (i), (ii), (iii), (iv), (v)

Tamamlayıcı Kriterler F, C, P

Tarihin şekillendirdiği arazilerde yaşamaya devam eden Altınkaya (Zerk) köyü tarihle iç içe yaşam sürdürmekte ve geçmişin etkilerini halen hissetmektedir. Yerleşimde yaşayan insanlar bir yandan tarihin izlerini görmekte öte yandan yine bu alanda geleneksel üretim alanlarını yaşamlarını sürdürmek için canlı tutmaktadır.

Selge kenti ve kent kalıntılarının ötesinde geleneksel tarım terasları tarihle gelecek arasındaki bağ ve sürdürülebilirliği gözler önüne sermesi açısından önemlidir. Tarihe ve antik kalıntılara sonlamış durumlar olarak bakmanın ötesinde bağ kurmak ve bir anlamda tarihten fayda sağlamak açısından Selge antik tarım terasları önemli görülmektedir.

Selge antik kenti bölgesinde bilimsel açıdan kazı çalışmalarının ve incelemelerin hala yetersiz görülmesine karşın gün yüzünde olan simgelerinden geleneksel tarım teraslarını Dünya Mirası Kültürel Miras kriterleri açısından değerlendirmek ve böylelikle bu alana dikkat çekmek hedefler arasındadır.

\section{KAYNAKLAR}

Akdoğu, G. (2014). Kentleşme Sürecinde Kırsal Yerleşmelerde Yaşanan Peyzaj Değişimlerinin İrdelenmesi. T.C. İstanbul Üniversitesi Fen Bilimleri Enstitüsü Yüksek Lisans Tezi, İstanbul.

Akpınar, E. (2007). Türkiye'nin Dünya Mirası Listesi’ndeki Yeri Ve Yeni Bir Aday Önerisi. Erzincan Eğitim Fakültesi Dergisi Cilt-Sayı: 9-1 Yıl: 2007.

Antalya İl Kültür ve Turizm Müdürlüğü, (2018). http://www.antalyakulturturizm.gov.tr/TR67572/selge.html (Son erişim tarihi: 08.12.2018)

Antalya Valiliği, (2004). Kültür Envanteri; TC Antalya Valiliği İl Kültür ve Turizm Müdürlüğü Kültür Envanteri (Manavgat- Serik). İl Özel İdaresi Kültür Yayınları, Envanterler Dizisi:3, Antalya.

Atik, M., Altuntaş, A., (2011). Visions for Sustainability in Landscape Architecture and Heritage Conservation: Three Examples from Turkish Mediterranean, Antalya. Icanla International Conference of Landscape Architecture Projects: from Theory to Technical Implementation. New Tendencies and Perspectives, 29 May-3 June, 2011 St.Petersburg Russia, Book of Abstracts, pages 8-9.

Büyükyıldırım, G. (1991). Antalya Köprülü Kanyon Milli Parkı Ve Selge Antik Kenti Su Yapıları Üzerine Bir İnceleme. DSİ XIII. Bölge Müdürlüğü, Antalya.

Bean, G., E. (1999). Eski Çağ’da Güney Kıyılar. Arkeoloji Dizisi:002, 2. Basım, İstanbul. ISBN: 978-975-571-055.

Kap Yücel, S., D., Salt, E., (2018). Kültürel Peyzajların Tarihsel Süreç İçerisindeki Değişimlerinin Tespiti: Bursa İznik Örneği. Planlama 2018;28(1):40-55 doi: 10.14744/planlama.2018.46220.

Kunar, S. (1995). Side: Seleukia, Manavgat, Etenna, Selge, Köprülü Kanyon. Net Turistik Yayınları A.Ş., ISBN: 9754792682, 1. Baskı, İstanbul.

Maymand, (2018). Cultural Landscape of Maymand. http://maymand.ir/en_US/Pages/Gallery/DastKand_Maymand_Village (Son erişim tarihi: $07.12 .2018)$

Nolle, J. (2015). Sikkeler, Ağaçlar ve Alimler: Selge. Pisidia'nin Dağ Şehrinde Bir 'Doğa Tapınağı'. Koç Üniversitesi Suna \& İnan Kıraç Akdeniz Medeniyetleri Araştırma Merkezi (AKMED) Yayınları, ISBN: 9786054018239, İstanbul.

Strabon, (2009). Geographika, Kitap: XII-XIII-XIV, Antik Anadolu Coğrafyası, Arkeoloji ve Sanat Yayınları Antik Kaynaklar Dizisi:1, ISBN: 975-7538-20-5. 6. Baskı, İstanbul.

Taylor, K., (2011). Emergence Of Cultural Landscape Concepts Part 1. 
UNESCO, (2018a). World Heritage List. http://whc.unesco.org/en/list/ (Son erişim tarihi: $6.11 .2018)$

UNESCO, (2018b). Cultural Landscapes. http://whc.unesco.org/en/culturallandscape/\#2 (Son erişim tarihi: 12.11 .2018 )

UNESCO World Heritage Papers, (2009). http://unesdoc.unesco.org/images/0018/001870/187044e.pdf (Son erişim tarihi: 10.11.2018)

Val d'Orcia, (2018). Val d'Orcia. http://www.italia.it/en/travel-ideas/unesco-world-heritagesites/val-dorcia.html (Son erişim tarihi: 11.12.2018)

Von Lanckoronski, K., G., (1892). Pamphylia ve Pisidia kentleri, II. Cilt Psidia. Suna - İnan Kıraç Akdeniz Medeniyetleri Araştırma Enstitüsü Çeviri Dizisi-6, 2015. ISBN: 978-6054018-25-3.

Weltkulturerbe Wachau, (2018). Weltkulturerbe Wachau. https://www.weltkulturerbewachau.at/wein-tourismus/ (Son erişim tarihi: 10.12.2018)

Yalçın Coşkun, B., S. (2009). Kültürel Peyzaj Alanları ve Yöresel Mimarinin Bütünleşik Korunması, Muğla Çomakdağ Köyü Örneği. Mimar.ist, Sayı 2009/31, (s. 37-42).

\section{EXTENDED ABSTRACT}

Cultural landscapes are many areas of value that societies want to preserve and accumulate over time, and are an important part of the World Heritage List. In this context, in 1992 the World Heritage Committee recognized that cultural landscapes represent the birleşik unified work of nature and man "(UNESCO World Heritage Papers, 2009). The acceptance of cultural landscapes on the list is an effective step for both recognizing the area and protecting natural and cultural values.

There are 105 cultural landscapes in the World Heritage List. Among these areas, cultural landscape examples of rural nature were selected as areas to support this study. When looking at the existing rural cultural landscapes in the World Heritage List, there are many areas of different scales and qualifications. In this category, each rural area stands out with its different characteristics. Rural landscapes are shaped according to the traditions of the working societies as well as changing according to natural conditions (Dirik, 2005; Akdoğu, 2014). With this feature, rural qualifications are important in the evaluation of the Selge ancient agricultural terraces.

The study area is characterized by its rural characteristics and the heritage sites of the UNESCO World Heritage Cultural Landscape and the ancient city of Selge and the traditional agricultural terraces. World Heritage within the scope of the study The location where rural cultural landscapes were located was evaluated with its prominent characteristics over traditional area uses, selection criteria and complementary criteria. In the cultural landscapes of the World Heritage List, it is seen that the vineyards, traditional agricultural terraces, pastures and the areas that first emerged had a large place in the list. Turkey is seen as likely to take place among the cultural landscape in the heritage list in this regard and is spite of World Heritage Cultural Landscape between the Diyarbakır Castle is located in one area only in the cultural landscape from Turkey and Hevsel Gardens Cultural Landscape be prominent in many areas with traditional land uses.

In this study, the land use pattern and Selge agricultural terraces have been studied for thousands of years in terms of agricultural and rural characteristics in terms of World Heritage Cultural Landscapes. The study draws attention to the suitability of Selge ancient city and agricultural terraces to be included in the World Heritage List with their qualities and original values. The target in the selection of the study area is to emphasize that there is only one area within the World Heritage List Cultural Landscape between the UNESCO Cultural Heritage sites in our country and also an area in our country which also includes traditional area uses which are mostly seen in the heritage in this list.

The village of Altınkaya (Zerk), which continues to live in the lands shaped by the history, continues to live together with history and still feel the effects of the past. The inhabitants of the settlement, on the one hand, see the traces of history, on the other hand, keep the traditional production areas alive in order to survive.

Beyond the city of Selge and the ruins of the city, the traditional agricultural terraces are important for revealing the link between history and future and sustainability. The historical 
terraces of Selge are considered important in terms of linking beyond historical and ancient ruins.

Although the excavations and investigations of the ancient city of Selge are still insufficient, the aim is to evaluate the traditional agricultural terraces in terms of World Heritage Cultural Heritage criteria and to draw attention to this area. 